\begin{tabular}{|c|c|c|}
\hline \hline & $\begin{array}{c}\text { International Journal of Current Research in } \\
\text { Biosciences and Plant Biology }\end{array}$ \\
\hline EXCELLENT \\
PUBLISHERS
\end{tabular}

\title{
Antimicrobial Efficacy and Phytochemical Analysis of Calotropis gigantea (L.) R.Br.
}

\author{
Jim Thomas ${ }^{1 *}$, M. Suresh Kumar ${ }^{2}$, E.G. Wesely ${ }^{3}$ and Nathan Vinod Kumar ${ }^{4}$ \\ ${ }^{I}$ Department of Biotechnology, Muthayammal College of Arts and Science, Rasipuram, Namakkal Dist., Tamil Nadu, India \\ ${ }^{2}$ Department of Zoology, Muthayammal College of Arts and Science, Rasipuram, Namakkal Dist., Tamil Nadu, India \\ ${ }^{3}$ Department of Botany, A.A. Government Arts College, Namakkal - 637 002, India \\ ${ }^{4}$ National Institute of Oceanography-CSIR, Regional Centre, Cochin - 682 018, Kerala, India
}

*Corresponding author.

\begin{abstract}
The leaves and root samples of Calotropis gigantea were screened for its antimicrobial and phytochemical activities. Solvent extraction was performed using solvents namely methanol, ethanol, isopropanol and hexane. Phytochemical analysis revealed the presence of alkaloids, flavonoids, steroids, terpenoids, phenols and tannins in both root and leaves extracts. In leaves, anthraquinone was present. In case of hexane only alkaloids, tannins and carbohydrates were present. Antimicrobial activity was performed against opportunistic pathogenic bacterial strains such as Escherichia coli, Pseudomonas aeruginosa, Staphylococcus aureus and Klebsiella pneumonia using the disc diffusion method. The methanolic extract of root of Calotropis gigantea inhibited P. aeruginosa with a maximum zone of inhibition $(18 \pm 0.5 \mathrm{~mm})$ at the maximum concentration tested. Hexane extract exhibited low inhibition activity. Similarly, the methanolic extract of leaves exhibited a zone of inhibition of $27 \pm 0.8 \mathrm{~mm}$ against $P$. aeruginosa. The results were compared with standard antibiotics ampicillin, vancomycin and tetracycline. In present study, methanolic extract was found to exhibit effective anti-bacterial properties which could be attributed to the presence of phytochemical present in the extract.
\end{abstract}

\section{Introduction}

There is an ever increasing demand for phytomedicines in the modern society due to the alarming issues on side effects of modern medicines. A major challenge in the current days is the problems associated with antibiotic resistance mechanism. The continued emergence or persistence of drug resistant organisms and the increasing evolutionary adaptation by pathogenic organisms to commonly used antimicrobials have reduced the efficacy of antimicrobial agent currently in use (Fahnsworth and Morris, 1976). To resolve this issue, we are forced to prospect new drug molecules suitable for therapeutically applications. India has many traditional and herbal based medicine systems like Ayurveda which uses herbal formulation and commonly available flora for curing many disorders.

Calotropis gigantea belonging to Asclepidaceae family is a xerophytic, erect shrub, growing widely throughout the tropical and subtropical regions around the world and widely seen throughout India. Plants contain many biologically active molecules with different medicinal properties (Newman et al., 2003). The latex of $C$. 
gigantea has been well studied for its medicinal properties. It is used as purgative, for gastrointestinal irritant and abortion inducer (Chopra et al., 1956; Maurya et al., 2004; Nadkarni, 2014), for toothache, earache, headache, sprain and stiff joints (Manandhar and Manandhar, 1990).

The present study focuses on the preliminary phytochemical screening and evaluation of antimicrobial efficacy of leaf and root extract of Calotropis gigantea. Though many studies exist on the same, there are more studies required on the phytochemical extractability and its efficiency in inhibiting the pathogenic bacterial strains. Moreover, the efficacy of extract for inhibitory action can also be depended on the phytochemicals extracted and the solvent system used. The opportunistic pathogens selected in the study were multidrug resistant and hence the inhibition using the extract was more relevant.

The antimicrobial activity of plants is mainly attributed to the phytochemicals present. Hence, the presence of phytochemicals is also depend on the environment they are inhabitant and may change. This study hence, deals with the preliminary phytochemical analysis of leaf and root extract of $C$. gigantea and to understand their inhibitory efficiency against the bacterial strains.

\section{Materials and methods}

\section{Collection of plant material}

Leaf and root samples of Calotropis gigantea (L.) R.Br. were collected from Namakkal District of Tamil Nadu, India. The samples were shade dried and powdered for extraction of phytochemicals.

\section{Preparation of leaf extract}

C. gigantea leaves and root powders were subjected to Soxhlet extraction. Methanol, ethanol, isopropanol and hexane were used for phytochemical extraction in the order of polarity. The extraction was performed overnight to obtain concentrated extracts. Further the extracts were concentrated using a rotary evaporator and was stored at $4^{\circ} \mathrm{C}$ for further use.

\section{Phytochemical analysis of extract}

Phytochemical evaluation of the leaf and root extract of C. gigantea prepared using four solvents was performed using the standard procedures. Different phytochemicals, namely flavonoids, saponins, steroids, terpenoids, tannins, carbohydrates and glycosides were screened (Srividya and Chandra, 2015).

\section{Agar diffusion assay}

The modified agar disc diffusion method was employed. $24 \mathrm{hrs}$ old bacterial cultures of Escherichia coli, Klebsiella pneumoniae, Pseudomonas aeruginosa and Streptococcus aureus were inoculated onto Muller Hinton agar (MHA) media (HiMedia, Mumbai) by spread plate technique. Sterile discs of $6 \mathrm{~mm}$ diameter were impregnated in various concentrations of extracts and placed onto MHA plates. Extracts were prepared by dissolving the concentrates in DMSO (Dimethyl Sulfoxide) to obtain $62.5,125,50$ and $500 \mu \mathrm{g} / \mathrm{mL}$. The plates were sealed and incubated at $32 \pm 2{ }^{\circ} \mathrm{C}$ for $24 \mathrm{hrs}$. The diameter of zone of inhibition was recorded after the incubation period. All the experiments were conducted in triplicates and values are expressed as mean \pm standard deviation (Jim et al., 2016).

\section{Results and discussion}

\section{Phytochemical screening}

Leaf and root extracts were prepared using solvents namely methanol, ethanol, isopropanol and hexane. Phytochemical analysis was performed to understand the extractability of various phytochemicals using these four solvents. The results of phytochemical screening of leaves and roots are enlisted in Table 1 and Table 2 respectively. In the present study, it was observed that there was presence of alkaloids, flavonoids, steroids, terpenoids, phenols and tannins in both root and leaves extracts. In leaves, anthraquinone was present. The extract from leaves contain more phytochemicals. This observed was in hand with a previous report of Singh et al. (2014) who reported large number of bioactive secondary molecules like alkaloids, tannins, saponin, flavonoids, glycoside in the leaf extract. It was reported that, saponins were the only phytochemical extracted from root using various solvents (Kori and Alawa, 2014). The n-hexane extracts were poor in their phytochemical contains. In the study, hexane extraction yielded alkaloids, tannins and carbohydrates. Apart from leaves and root, the latex in the leaves and stem also possess phytochemicals. Latex of $C$. gigantea had the presence of phytochemicals namely alkaloids, steroids, cardiac glycosides and terpenes (Ishnava et al., 2012). 
Table 1. Phytochemical screening of leaf extract of $C$. gigantea.

\begin{tabular}{lllll}
\hline Phytochemicals & Extracts & & Isopropanol & Hexane \\
\cline { 2 - 5 } & Methanol & Ethanol & + & + \\
Alkaloids & + & + & - & - \\
Flavonoids & + & + & + & - \\
Steroids & + & + & - & - \\
Terpenoids & + & - & - & - \\
Anthraquinones & - & - & - & - \\
Phenol & + & + & + & + \\
Tannins & + & + & + & + \\
Carbohydrates & + & + & & + \\
\hline
\end{tabular}

Table 2. Phytochemical screening of root extract of $C$. gigantea.

\begin{tabular}{lllll}
\hline Phytochemicals & Extracts & & Isopropanol & Hexane \\
\cline { 2 - 5 } & Methanol & Ethanol & - & + \\
Alkaloids & + & - & + & - \\
Flavonoids & + & - & + & - \\
Steroids & + & + & - & - \\
Terpenoids & + & - & - & - \\
Anthraquinones & + & - & - & - \\
Phenol & + & + & + & + \\
Tannins & + & + & + & + \\
Carbohydrates & + & & & + \\
\hline
\end{tabular}

\section{Antimicrobial activity of leaf extract}

Antimicrobial activity of leaf extract of Calotropis gigantea prepared using four different solvents is depicted in Fig. 1 (a-d). The leaf extracts of C. gigantea impart sufficient inhibitory actions against the test microbe ranging from $10 \pm 0 \mathrm{~mm}$ to $27 \pm 0.8 \mathrm{~mm}$ diameter inhibitory zones. The results were compared with standard antibiotics ampicillin, vancomycin and tetracycline. Methanolic extract exhibited an increasing trend of inhibition with increase in extract concentration. Maximum inhibition was observed in case of P.aeruginosa followed by $S$. aureus and K. penumoniae. In case of ethanolic leaf no inhibition was observed at lower concentrations. Maximum inhibition efficiency was observed against $E$. coli at $500 \mu \mathrm{g} / \mathrm{mL}$. Isopropanol extract, at low concentrations, exhibited no inhibition against the tested bacteria. Maximum inhibition was observed for $P$. aeruginosa and $K$. penumoniae at highest extract concentration tested $(500 \mu \mathrm{g} / \mathrm{mL})$. At 125 $\mu \mathrm{g} / \mathrm{mL}$ concentration, no inhibition was observed against $S$. aureus. Similarly, hexane extract exhibited no inhibition at low concentrations. At $250 \mu \mathrm{g} / \mathrm{mL}$ inhibition was observed against $P$. aeruginosa and $K$. penumoniae and no inhibition for E. coli and S. aureus. Maximum inhibition efficiency was observed against $K$. penumoniae at $500 \mu \mathrm{g} / \mathrm{mL}$. The bacterial strains $B$. cereus and $S$. aureus were susceptible to plant extracts with zone of inhibition $(\geq 20 \mathrm{~mm})$ diameter respectively
(Seniya et al., 2011) and out of the hexane and benzene extracts only limited inhibition was observe in benzene extract against the E. coli only (Kori and Alawa, 2014).

\section{Antimicrobial activity of root extract}

Antimicrobial activity of root extract of Calotropis gigantea prepared using four different solvents is depicted in Fig. 2 (a-d). The root extracts of C. gigantea impart sufficient inhibitory actions against the test microbe ranging from $10 \pm 0.5$ to $18 \pm 0.5 \mathrm{~mm}$ diameter inhibitory zones. Methanolic extract exhibited an increasing trend of inhibition with increase in extract concentration. Maximum inhibition was observed in case of $S$. aureus followed by $K$. penumoniae. In case of ethanolic root extract, inhibition was observed even at lower concentrations. At $62.5 \mu \mathrm{g} / \mathrm{mL}$ concentration, no inhibition was observed against $K$. penumoniae. Maximum inhibition efficiency was observed against $P$. aeruginosa at $500 \mu \mathrm{g} / \mathrm{mL}$. Ethanolic extract was not effective against $K$. penumoniae. In case of Isopropanol extract, maximum inhibition was observed for $K$. penumoniae with increasing extract concentrations. The extract was also effective against $E$. coli and $P$. aeruginosa. Similarly, hexane extract exhibited maximum inhibition for $S$. aureus and $P$. aeruginosa. Generally, the efficient extract for antimicrobial formulation was methanolic extract. In a previous study, the extract showed a high concentration ranging from 
0.25 to $0.5 \mathrm{mg} / \mathrm{mL}$ effective against $B$. cereus, B. subtilis, E. coli, K. pneumonia, M. luteus, S. aureus and $S$. typhi respectively. Methanol extract has value of MIC in range of 0.5 to $2.0 \mathrm{mg} / \mathrm{mL}$ (Seniya et al., 2011).The aqueous, ethanolic and acetonic extracts of root of $C$. gigantea impart sufficient inhibitory actions against the test microbe ranging from $10 \mathrm{~mm}$ to $16 \mathrm{~mm}$ diameter inhibitory zones (Kori and Alawa, 2014). Hence, compared to the earlier reports, a good inhibition was achieved in the present study.
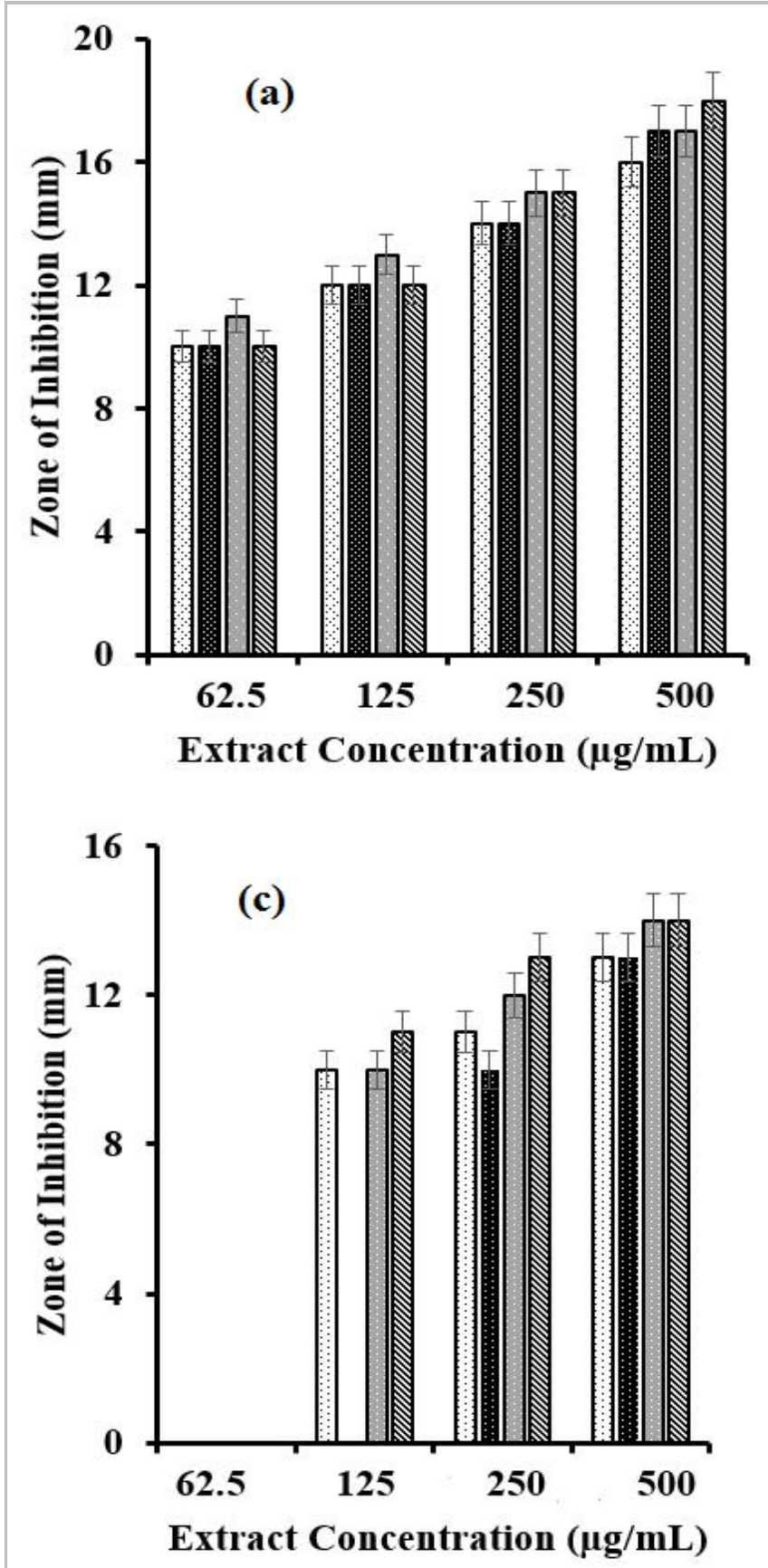
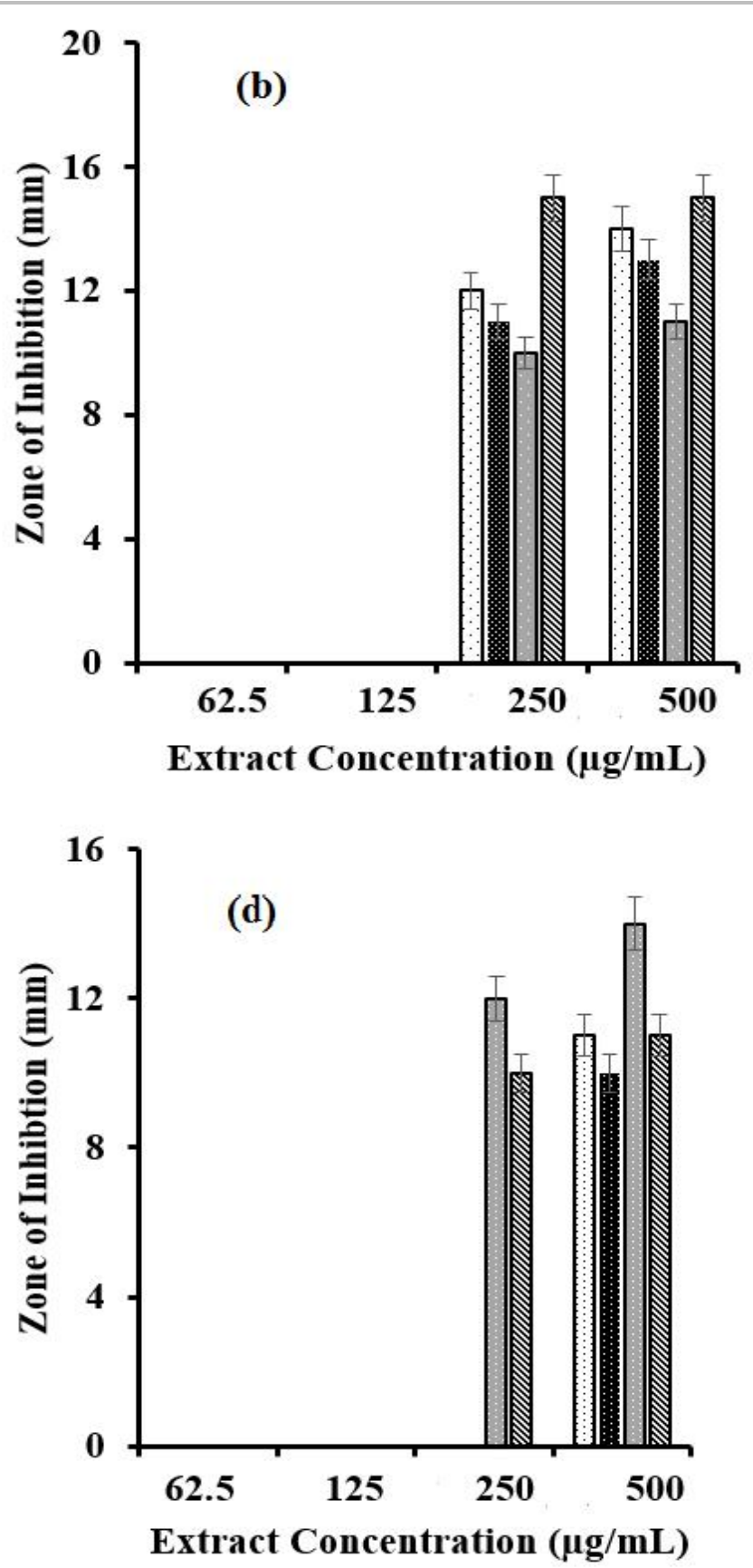

๑Escherichia coli

a Staphylococcus aureus $\square$ Klebsiella pneumoniae

\& Pseudomonas aeruginosa

Fig. 1: Antimicrobial activity of leaf extract of Calotropis gigantea using different solvent extraction: (a) Methanolic extract, (b) Ethanolic extract, (c) Isopropanol and (d) Hexane. 

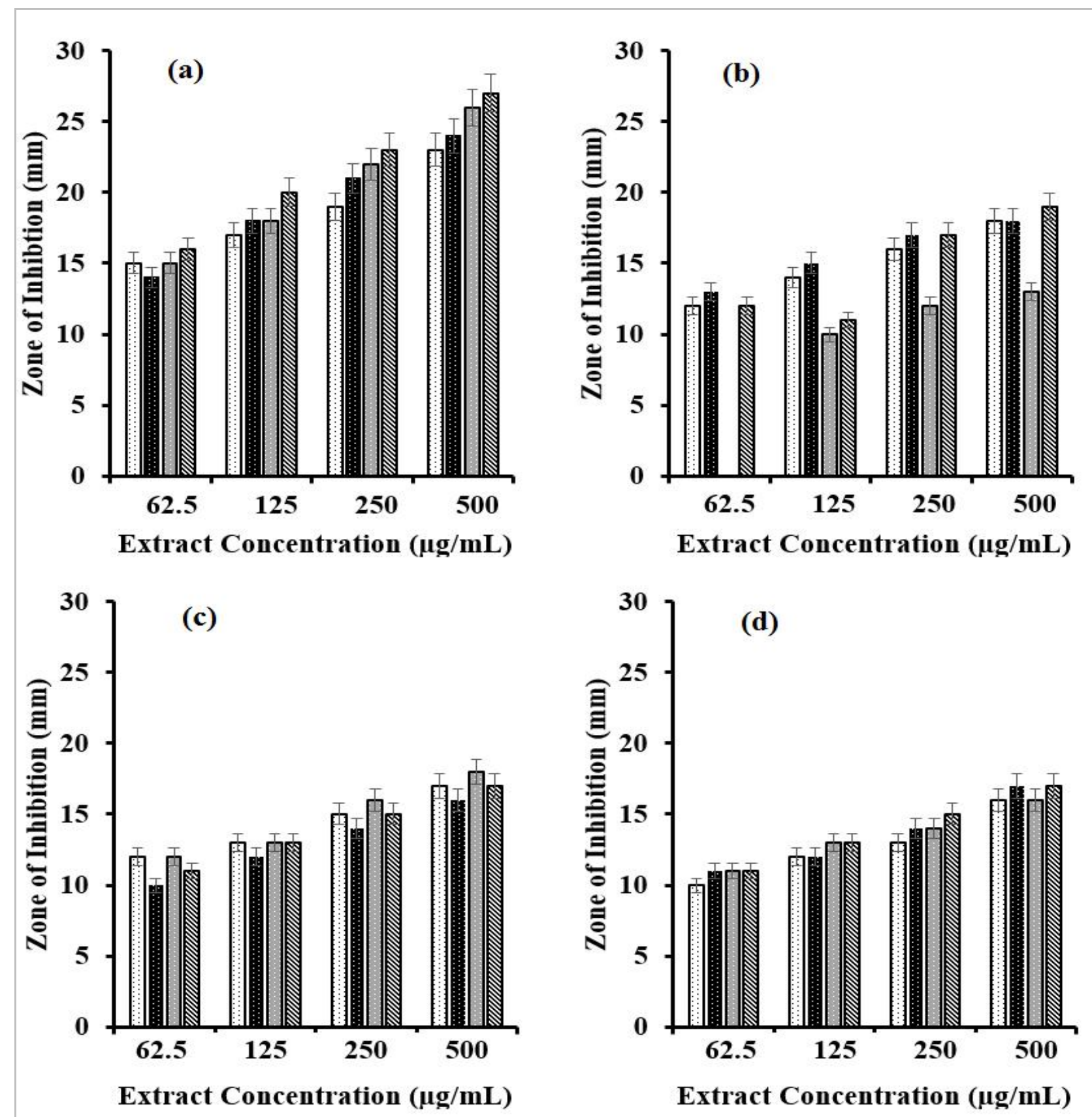

\section{QEscherichia coli $\quad$ KKlebsiella pneumoniae \\ a Staphylococcus aureus \& Pseudomonas aeruginosa}

Fig. 1: Antimicrobial activity of root extract of Calotropis gigantea using different solvent extraction: (a) Methanolic extract, (b) Ethanolic extract, (c) Isopropanol and (d) Hexane.

\section{Conclusion}

This study revealed that the various solvent extract of leaves of $C$. gigantea were suitable as an antimicrobial agent against $P$. aeruginosa followed by $S$. aureus and $K$. penumoniae. Root extract exhibited inhibition against
$S$. aureus followed by $K$. penumoniae. The phytochemical analysis revealed that the extract possesses alkaloids, flavonoids, steroids, terpenoids, phenols and tannins in both root and leaves extracts which may be attributed to the antimicrobial effect of the extract. The hexane was not effective for 
phytochemical extraction and had exhibited a low inhibition against tested bacteria. $C$. gigantea leaves were more potential than root and further study is required to trace out the molecule responsible for the inhibitory action.

\section{Conflict of interest statement}

Authors declare that they have no conflict of interest.

\section{Acknowledgement}

Authors extend acknowledgement to the Department of Biotechnology, and Management of Muthayammal college of Arts and Science, India for necessary infrastructure facilities. Dr. Wesley and Vinod Kumar thank AA Government Arts College, Namakkal and National Institute of Oceanography-CSIR for their support.

\section{References}

Chopra, R. N., Nayar, S. L., Chopra, I. C., 1956. Glossary of Indian Medicinal Plants. CSIR, New Delhi.

Fahnsworth, N. R., Morris, R. W., 1976. Higher plants: The sleeping giants of drug development. New York. Amer. J. Pharm. 147(2), 46-52.

Ishnava, K. B., Chauhan, J. B., Garg, A. A., Thakkar, A. M., 2012. Antibacterial and phytochemical studies on Calotropis gigantia (L.) R. Br. latex against selected cariogenic bacteria. Saudi J. Biol.
Sci. 19(1), 87-91.

Jim, T., Suresh Kumar, M., Vinod Kumar,N., Wesely, E.G., Rajasekara Pandian, M., 2016. Antimicrobial activity and phytochemical evaluation of aqueous extract of Artocarpus hirsutus Lam. Bark. Global J. Res. Anal. 5(6), 1-3.

Kori, P., Alawa, P., 2014. Antimicrobial activity and phytochemical analysis of Calotropis gigantea root, latex extracts. IOSR J. Pharm. 4(6), 7-11.

Manandhar, N.P.,Manandhar, M.P., 1990. Folklore medicine of Chitwan District, Nepal. Ethnobot. 2, 33-35.

Maurya, R., Srivastava, S., Kulshreshta, D. K., Gupta, C. M., 2004. Traditional remedies for fertility regulation. Curr.Med.Chem., 11(11), 1431-1450.

Nadkarni, A. K., 2014. Indian Materia Medica. $3^{\text {rd }}$ Edn. Volume 2. Popular Book Depot, Bombay.

Newman, D. J., Cragg, G. M., Snader, K. M., 2003. Natural products as sources of new drugs over the period 1981-2002. J. Nat. Prod. 66(7), 1022-1037.

Seniya, C., Trivedia, S. S., Verma, S. K., 2011. Antibacterial efficacy and phytochemical analysis of organic solvent extracts of Calotropis gigantea. J. Chem. Pharm. Res. 3(6), 330-336.

Singh, S., Singh, S., Mishra, R. M., Shrivastava, M. P., 2014. Preliminary phytochemical screening of Calotropis gigantea leaf. Int. J. Sci. Res. Pub. 4(2), 12-15.

Srividya, N., Chandra, M., 2015. Evaluation of bioactive compounds and antioxidant activity of some wild fruits by in-vitro assays. Int. J. Pharma. Sci. Res. 6(1), 233.

\section{How to cite this article:}

Jim, T., Suresh Kumar, M., Wesely, E. G., Vinod Kumar, N., 2017. Antimicrobial efficacy and phytochemical analysis of Calotropis gigantea (L.) R.Br. Int. J. Curr. Res. Biosci. Plant Biol. 4(9), 79-84.

doi: https://doi.org/10.20546/ijcrbp.2017.409.012 